Article

\title{
Urban Land Allocation Model of Territorial Expansion by Urban Planners and Housing Developers
}

\author{
Carolina Cantergiani * (1) and Montserrat Gómez Delgado \\ Department of Geology, Geography, and Environment, University of Alcala; 28801 Alcalá de Henares, Spain; \\ montserrat.gomez@uah.es \\ * Correspondence: carolina.carvalho@uah.es; Tel.: +34-91-885-5263
}

Received: 21 September 2017; Accepted: 27 December 2017; Published: 29 December 2017

\begin{abstract}
Agent-based models have recently been proposed as potential tools to support urban planning due to their capacity to simulate complex behaviors. The complexity of the urban development process arises from strong interactions between various components driven by different agents. AMEBA (agent-based model for the evolution of urban areas) is a prototype of an exploratory, spatial, agent-based model that considers the main agents involved in the urban development process (urban planners, developers, and the population). The prototype consists of three submodels (one for each agent) that have been developed independently and present the same structure. However, the first two are based on a land use allocation technique, and the last one, as well as their integration, on an agent-based model approach. This paper describes the conceptualization and performance of the submodels that represent urban planners and developers, who are the agents responsible for officially launching expansion and defining the spatial allocation of urban land. The prototype was tested in the Corredor del Henares (an urban-industrial area in the Region of Madrid, Spain), but is sufficiently flexible to be adapted to other study areas and generate different future urban growth contexts. The results demonstrate that this combination of agents can be used to explore various policy-relevant research questions, including urban system interactions in adverse political and socioeconomic scenarios.
\end{abstract}

Keywords: urban land allocation model; agent-based model; spatial simulation of urban growth; urban planners; developers; urban modeling

\section{Introduction}

Urban growth is considered a complex phenomenon due to the strong interactions between different economic, social, environmental, cultural, and institutional components. A deeper understanding of how, why, and where these interactions occur is required in order to be able to plan the territory and create better futures for a constantly growing population. Thus, urban planning is fundamental, as is the need to comprehend and anticipate territorial changes. Modeling offers an alternative means to achieve this due to its capacity to create different possible future scenarios and depict the consequences of urban growth [1-3].

Recent decades have witnessed exponential growth in the use of exploratory models based on different techniques (e.g., stochastic, artificial intelligence, and fuzzy tolerance) in the field of simulation. Although cellular automata (CA) predominate [2], agent-based models (ABM) open new perspectives. Both were originally developed in the field of artificial intelligence with the aim of reproducing the knowledge and reasoning of several heterogeneous agents with the capacity for autonomous action in a specific environment, who at the same time need to coordinate to jointly solve planning problems [4]. 
However, the use of modeling as a tool to support urban planning has remained limited due to historical skepticism about modeling designed for this purpose [5-7]. Nevertheless, although few ABMs have been employed to address urban issues, other cellular models such as CA have gained more widespread acceptance [8-11]. This is confirmed in a review of urban simulation modeling techniques by Triantakonstantis and Mountrakis [2], who found that more than $80 \%$ of the publications analyzed had used a CA, whereas ABM only accounted for less than $10 \%$. These statistics must be placed in context, since CAs have a long history of being used for spatial modeling, whereas ABM are comparatively new in this field. Nevertheless, CAs pose some problems, for example when considering long distance interactions [3], thus paving the way for the use of $A B M$ in the urban modeling arena.

$\mathrm{ABM}$ techniques are particularly suitable in this field to gain a better understanding of the urban development process because they allow individual simulation of each agents' behavior and show how, in conjunction, their behavior produces changes in the territory in the form of urban growth. Hence, ABM provides a good laboratory for developing new models of cities, since they elucidate how different city elements interact and thus enable planners to better understand what might happen in the future $[3,12,13]$.

Another important issue to consider is the geographical scope of urban ABM, which varies according to purpose and encompasses multiple spatial scales, although always considering individual behavior. Thus, the literature contains models aimed at exploring local issues such as residential mobility [14] or emergency situations [3,15], and others with a broader, regional scope, for example those aimed at determining urban segregation or informal settlement formation [16-19]. Most have been designed to simulate housing and land market dynamics [20-27]. Consequently, the application of $\mathrm{ABM}$ has proved very versatile at different scales, including the sub-regional scale, here understood as the geographical level between the municipal and regional scale.

The sub-regional scale is particularly suitable for urban planning, since urban growth and its impacts can be better controlled at this level. This is especially useful in Spain, where planning is legally proposed at municipal level, with few examples at regional scale [28]; however, it is at this latter level where not only urban growth phenomena but also their territorial, environmental, and other associated impacts could be managed more efficiently. The lack of legal instruments at sub-regional scale has created serious problems, especially during the recent real estate boom [29-31].

Besides scale, a further advantage of ABM when simulating urban growth processes is their capacity to reproduce the behavior, actions, and interactions of the multiple agents involved, who may present diverse profiles (e.g., social, political, and economic). Urban planners and developers are unquestionably among the most important agents in urban growth, since they decide the amount of land to be converted to urban uses, as well as where development should first take place. The population represents another important agent in this process, since the population's behavior is responsible for the demand for new housing, in this case occupying the available dwellings generated by the two abovementioned agents.

Implementing an ABM that simultaneously considers both policy-making and the residential development process poses an enormous challenge in modeling due to the large number of variables to consider (accounting for both internal status and externalities), the spatial (sub-regional) and temporal scale (behavior may occur at different time intervals), and above all, the combination of top-down and bottom-up approaches. With respect to the spatial and temporal scale, it is assumed that these are strictly linked to the kind of data used. Many models developed to study changes observed at the urban level consider stylized data in a hypothetical world. Artificial cities and rules are constantly being created in order to test these models and their underlying theories [21,22,26,32].

Although some independent allocation models have been used to simultaneously simulate both levels of the planning process (policy-making by urban planners and residential expansion by developers), only a few ABMs have been aimed at considering both when simulating urban growth at the sub-regional scale [33-35]. Some of these have considered the environment or urban planners as agents, albeit not with the same goal $[18,20,36,37]$. In contrast, many urban ABMs consider 
developers as agents, mostly focusing on land market dynamics [21-23,32]. Similar models have accounted for both agents [36-39], although neither coincided with the purpose of modeling, which is to test and explore the urban process or the system itself. The closest example would be the study by Ligmann-Zielinska et al. [27], who developed a model using these three agents, although an independent deterministic model rather than an ABM was developed separately in order to simulate the typical top-down process of planning.

In line with these precedents, the objective of the present study was to create a model (AMEBA) in order to address the abovementioned gaps by simulating the urban development process at the sub-regional scale considering urban planners, developers, and the population, while simultaneously addressing the challenge of acting at heterogeneous intervals. This paper discusses the first and second submodels of the prototype, which adopt a more deterministic rather than stochastic approach, and were thus based on an urban land allocation model. The population submodel represents a parallel stage of this research and takes a stochastic approach to the occupation of newly developed areas, rather than the territorial expansion presented here. Since this latter forms part of the final integrated model, it is briefly introduced in the explanation of the model structure, but is not discussed further.

AMEBA has been developed as a prototype with three submodels developed independently on the same ABM platform, endowing it with sufficient flexibility to be adapted to other study areas and reproduce different future urban growth contexts. The submodels and the final prototype were created, fed, and tested using empirical data on a specific area in Spain, the Corredor del Henares. The sub-regional profile of the study area presents substantial socioeconomic and urban development diversity, and thus represents a suitable area to test the model.

Following this introduction, Section 2 gives a conceptual overview of the prototype (with three integrated submodels), and describes the study area, model structure, and other technical issues (platform and database). Section 3 reports on the implementation of the submodels that address territorial expansion (individually and in conjunction), the simulation experiments, and the validation process. Section 4 concludes the paper with a discussion of the submodels' capabilities and limitations, and directions for future research.

\section{Testing Area, Conceptual Model, and Data}

As previously mentioned, ABM are suitable for studying complex issues, and therefore could serve as a valuable tool to support urban planning processes. This section presents the conceptual model of the prototype (AMEBA), describing its structure, platform, and database, as well as the variables used to test the model in the study area.

\subsection{Testing Area}

The metropolitan area of Madrid has become one of the most dynamic areas of urban growth in the Iberian Peninsula and Europe [40]. It has three main urban growth corridors, each with their own defining characteristics (Figure 1). The study area encompassed 18 municipalities in the Region of Madrid selected from the northeast corridor, known as the Corredor del Henares, which runs from Madrid to Guadalajara (the capital of the neighboring region). This area is home to almost 600,000 inhabitants [41], covers $624 \mathrm{~km}^{2}$, and is strongly influenced by its proximity to the city of Madrid. In addition, it is a particularly dynamic area in urban and demographic terms, with substantial internal sociodemographic and urban development differences. This complexity is further increased by the lack of regulation aimed at solving territorial problems at the regional level, rendering it an ideal laboratory to test the prototype reported here. 


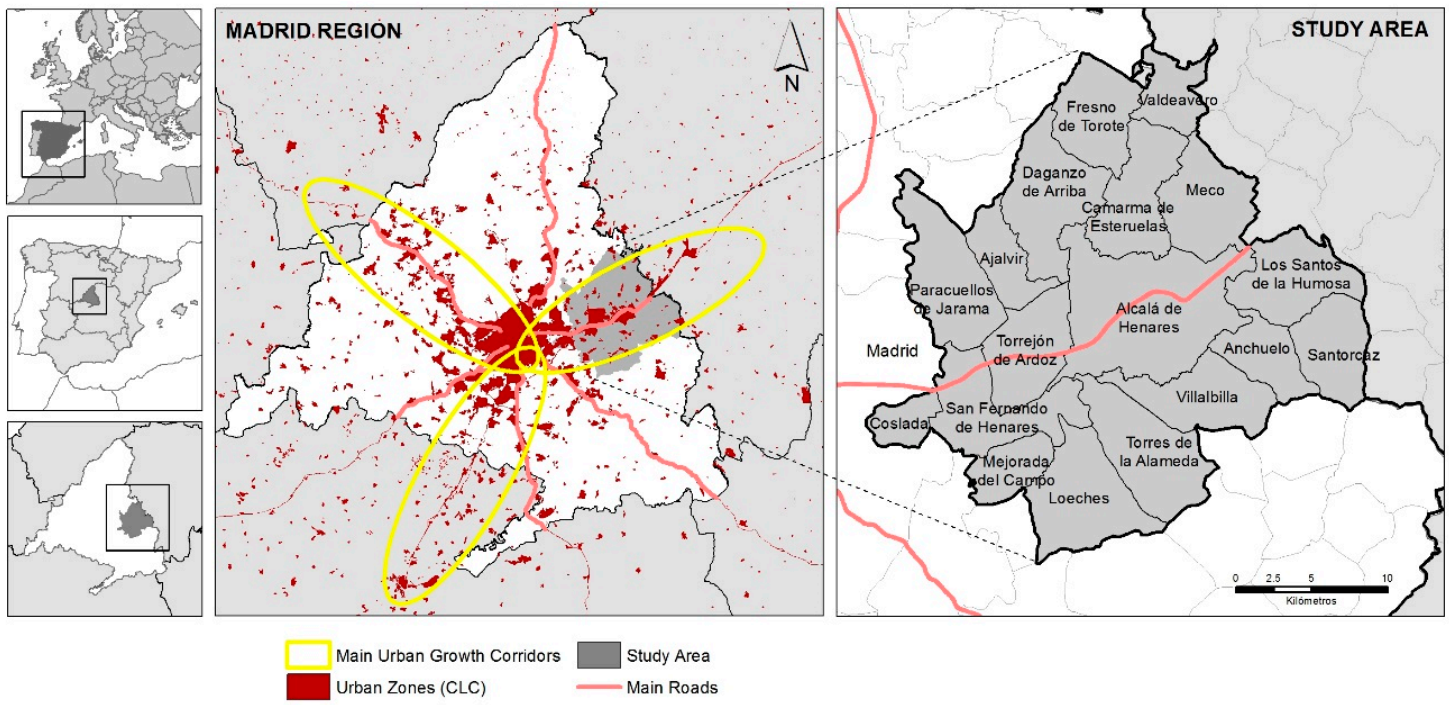

Figure 1. Urban corridors in the region of Madrid and study area.

The general urban growth trends identified in the main Spanish cities in the period of economic wealth (1997-2007) indicate rapid and chaotic urban development. This coincided with the housing bubble, subsequently followed by a stable period of consolidation [42-44]. Such trends have been witnessed in many other European urban areas in countries, such as Italy, Croatia, and France, mainly associated with their principal cities and coastal zones [45,46].

\subsection{Prototype Structure, Platform and Database}

The urban growth process at the regional scale could be theoretically and logically described as a three-stage process involving three types of agent: urban planners, developers, and the population [47]. The first two are responsible for the territorial expansion itself, while the latter represents the occupation of the territory, and all three converge to shape a complex urban system. The urban growth process starts with the identification of new potential urban areas by urban planners in line with national, regional, and local policies. In the second stage, developers choose where to promote new residential developments. Finally, the population selects where to live based on their individual preferences and according to their income possibilities. Although other elements may also be involved in the urban development process (such as infrastructure expansion or political guidelines), these would have been difficult to include in our model, so we decided to limit our agents to these three. Each of them is considered in an independent submodel with different characteristics. The first represents the typical deterministic, top-down process, while the second may be considered a transition between deterministic and stochastic approaches, and the third could be considered the closest representation of an ABM as we understand it (using a bottom-up approach), where complex interactions between agents are represented stochastically. The three of them are coordinated separately before subsequent integration in a final model, where outputs and inputs feed each other continuously. It is worth mentioning that the model is explicitly spatial, so all variables are spatially distributed.

The prototype is intended to be as useful as possible, and therefore it was constructed using an adaptable structure of submodels, each covering a critical variable in the urban growth process. This approach was adopted in response to the low impact that urban growth simulations have had on real-life planning processes, due to their closed architecture and the high amount of data needed to run them, not commonly available in many regions or countries [2].

As presented in Cantergiani et al. [48] the submodels are described below:

The first submodel (urban planner) simulates the urban planner's decision-making process, which consists of selecting new areas for urban development according to physical restrictions (e.g., protected 
areas, high slopes, or proximity to water bodies), distance to elements of interest (e.g., roads or consolidated urban areas), and the amount of growth required to meet existing demand. These criteria are set as parameters and can be modified at initialization to generate different scenarios.

The second submodel (developer) focuses on the developer's decision-making process regarding new residential developments. As part of their behavior, developers must decide where to build new housing, how many new developments must be built, their capacity, and their target economic group. This process takes into account the legal status of the territory (defined by urban planners in the first submodel), as well as the areas that will optimize their profits.

The third submodel (population) simulates the process of residential location choice and occupation by the population. In this case, different agents look for the best place to move according to their purchasing power and location preferences, which may include distance to the public transport network, education facilities, and other factors.

The flowchart in Figure 2 shows how the submodels are integrated and where the result of each submodel feeds into the next in a chain-like process.

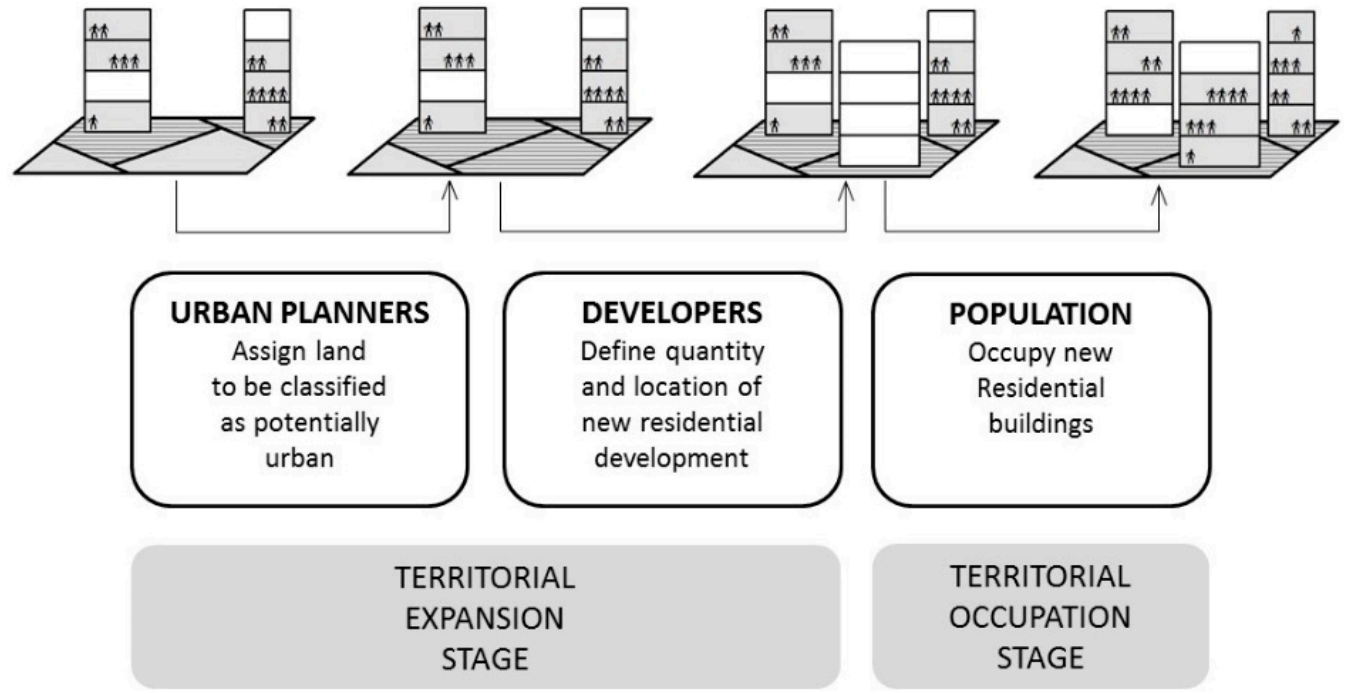

Figure 2. Integrated decision model to simulate urban growth.

The conceptual model considers two components for the three agents: territorial availability (TA) and spatial interest criteria (SIC). The first (TA) indicates potential areas taking into account spatial restrictions. For urban planners, it considers the limits imposed by legal regulations (e.g., master plans, law on protected areas) and physical urban development restrictions (e.g., along rivers, steep slopes) to spatially delineate potential areas for development. For developers, TA restricts the area to those classified as potentially urban. The second component (SIC) represents attractiveness, which indicates the preferences of each agent regarding the distance to given spatial elements. For urban planners, these include roads, public facilities, hazardous areas, agricultural productivity, and existing urban fabric, while for developers they include roads, public transport stops, existing urban fabric, and status of the existing residential stock. Due to the flexibility of each submodel of the prototype, several variables can be selected to represent these components and run the model [47], although here we only report those tested in the study area.

The platform used to develop the prototype was NetLogo v.5.3.1 (Center for Connected Learning and Computer-Based Modeling, Northwestern University, Evanston-IL, IL, USA) [49], which met the technical requirements and presents many advantages. To name a few, it has an intuitive and simple interface, it is widely used for similar applications, it is user-friendly, and it is open source. Moreover, it enables simple connection with geographical databases through a Geographic Information System (GIS) extension, fundamental for spatial analysis. For instance, this connection facilitates the 
flexibility required for adaptation to other study areas, with different input data in terms of extension or resolution.

The submodel interface consists of three sections: (i) an input box where geographical information is called up and spatially represented in a visualization panel; (ii) an area where the user sets the initial parameters that will define the scenarios to simulate; and finally (iii) a third area where the results are represented in the form of graphs, spatial distribution, and an external matrix containing statistical references (Figure 3).

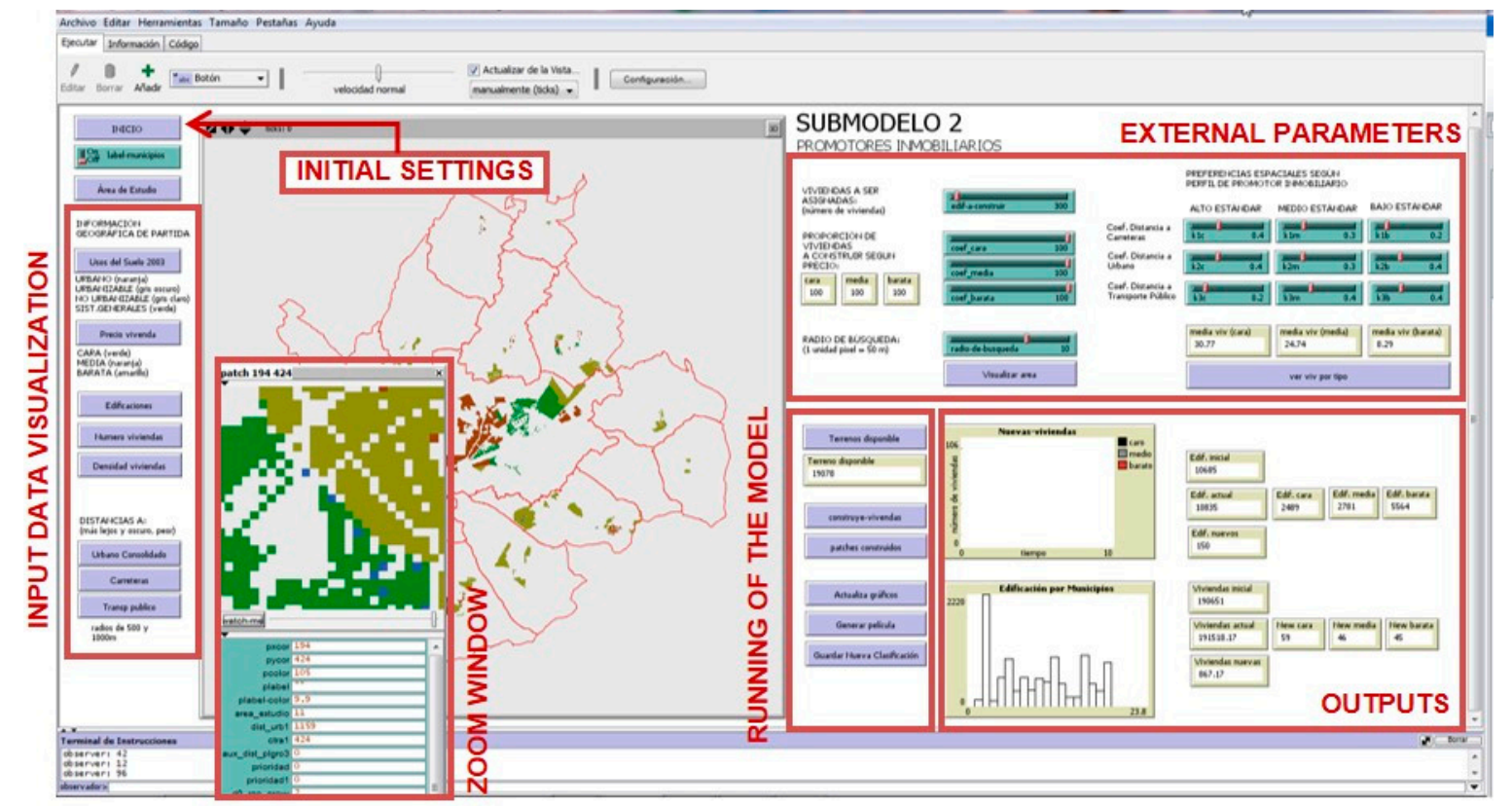

Figure 3. Distribution of the functional blocks in the interface (common for all submodels).

All submodels have a similar interface, differing only in the number and kind of external parameters to be set, and obviously in the expected outputs. Since a set of parameters can be freely modeled, users can adapt the model to their specific context and generate different future urban growth scenarios.

Bearing in mind the regional scale and main drivers of urban growth in the context cited and other similar contexts, a considerable effort was made to compile the most appropriate alphanumerical and geographical information, always considering the territorial component. Although they might form part of the process, statistical components were only incorporated into the model when they could be spatially represented (such as price and income distribution). Other variables, such as traffic flows, global climate change, mobility, and time variation, were not included at this stage for the abovementioned reasons, although we recognize they must play a partial role in the evolution of the phenomenon studied.

The input data used to implement the submodels were selected to reflect the drivers of urban growth, empirical knowledge of urban growth trends in the study area $[47,48,50,51]$, and the most commonly used variables in other studies $[8,33]$. These latter included the municipal boundaries (surface), zoning status (surface), and housing distribution (pixel) used by agents to assess specific environments and conditions, as well as the other spatial information indicated in Table 1 below. These were represented by pixels measuring $50 \times 50 \mathrm{~m}$. Once data had been collected, they were transformed into determinants for subsequent use in the model. 
Table 1. Description of determinants, based on input data, incorporated into the prototype.

\begin{tabular}{|c|c|c|c|}
\hline Data Layer & Scale & Origin & Determinant and Description \\
\hline $\begin{array}{c}\text { Census zones and associated } \\
\text { statistical data }\end{array}$ & $1: 1000$ & INE (2001) & $\begin{array}{l}\text { Distance to consolidated urban zones } \\
\text { Contributes to determination of } \\
\text { agents' preferences }\end{array}$ \\
\hline Zoning status & $1: 50,000$ & $\begin{array}{l}\text { Department of Environment, } \\
\text { Housing and Land Use } \\
\text { Planning, Region of Madrid } \\
\text { (2006) }\end{array}$ & $\begin{array}{c}\text { Land classification (reclassified as urban, } \\
\text { non-building, and potentially urban) } \\
\text { Functions as the legal constraint on } \\
\text { agents' actions }\end{array}$ \\
\hline $\begin{array}{l}\text { Natural Protected Zones } \\
\text { (Spanish initials: ENP) }\end{array}$ & $1: 50,000$ & $\begin{array}{l}\text { Environment Database of } \\
\text { Spanish Ministry of the } \\
\text { Environment (2012) }\end{array}$ & \multirow{3}{*}{$\begin{array}{l}\text { Restricted areas (sum of individual } \\
\text { restrictions spatially distributed) } \\
\text { These act as a mask under which agents } \\
\text { cannot intercede }\end{array}$} \\
\hline Buffer along main water bodies & $1: 25,000$ & BCN 25/CNIG, IGN (2008) & \\
\hline Slope (origin: Digital Terrain Model) & $1: 50,000$ & BCN 25/CNIG, IGN (2012) & \\
\hline Land use and land cover & $1: 100,000$ & $\begin{array}{l}\text { CORINE Land Cover Project } \\
\text { of IGN (2000-2005) }\end{array}$ & $\begin{array}{l}\text { Agricultural productivity generated from } \\
\text { reclassification of the land use database } \\
\text { Agents state their preferences according to } \\
\text { the high, medium, or low level } \\
\text { of productivity }\end{array}$ \\
\hline $\begin{array}{l}\text { Urban facilities (health and } \\
\text { education, public transport, locally } \\
\text { unwanted land uses) }\end{array}$ & $1: 25,000$ & $\begin{array}{l}\text { NomeCalles Database of } \\
\text { Statistical Institute of Region } \\
\text { of Madrid (2005) }\end{array}$ & $\begin{array}{c}\text { Distance to each type of facility } \\
\text { This may indicate a higher or lower level } \\
\text { of interest }\end{array}$ \\
\hline $\begin{array}{l}\text { Cadastral data containing } \\
\text { information at parcel level (code, } \\
\text { municipality, use, year of } \\
\text { construction, area, centroid, etc.) }\end{array}$ & 1:1000 & $\begin{array}{l}\text { General Directorate for Land } \\
\text { Register, Ministry of Finance } \\
\text { and Public Administration } \\
\text { (2006) }\end{array}$ & $\begin{array}{l}\text { Aggregated data by pixel represent the } \\
\text { initial residential building distribution } \\
\text { Agents behave according to the } \\
\text { existing buildings }\end{array}$ \\
\hline $\begin{array}{l}\text { Network of national and } \\
\text { regional roads }\end{array}$ & $1: 25,000$ & BCN 25/CNIG, IGN (2008) & $\begin{array}{c}\text { Accessibility calculated as distance to the } \\
\text { road network } \\
\text { This may indicate a higher or lower level } \\
\text { of interest }\end{array}$ \\
\hline
\end{tabular}

INE: National Statistics Institute; BCN: National Cartographic Database; CNIG: National Center for Geographical Information; IGN: National Geographic Institute; ENP: Protected Natural Spaces.

\section{Implementation of the Territorial Expansion Simulation}

\subsection{Urban Planner Submodel}

The urban planner submodel simulates regional urban growth and represents the most general scale of the three submodels, indicating areas where it is legally permissible to construct new residential buildings. This submodel presents a simple and deterministic structure, since the behavior of urban planners generally reflects a top-down approach whereby decisions are made within a general plan by an institutional agent rather than by individuals (or by an individual representing an institution). Nonetheless, the allocation model was developed in NetLogo in order to facilitate integration into future submodels that might simulate agents' behavior using the bottom-up approach.

The expected result is useful for any urban planner, and represents a laboratory that allows the selection of new areas for reclassification as potentially urban (Figure 4), generated from their decision regarding the most suitable areas according to criteria that may differ depending on the agent's profile. Rather than testing the model with different types of urban planner, we only considered one type presenting different profiles that in turn could generate numerous scenarios. 


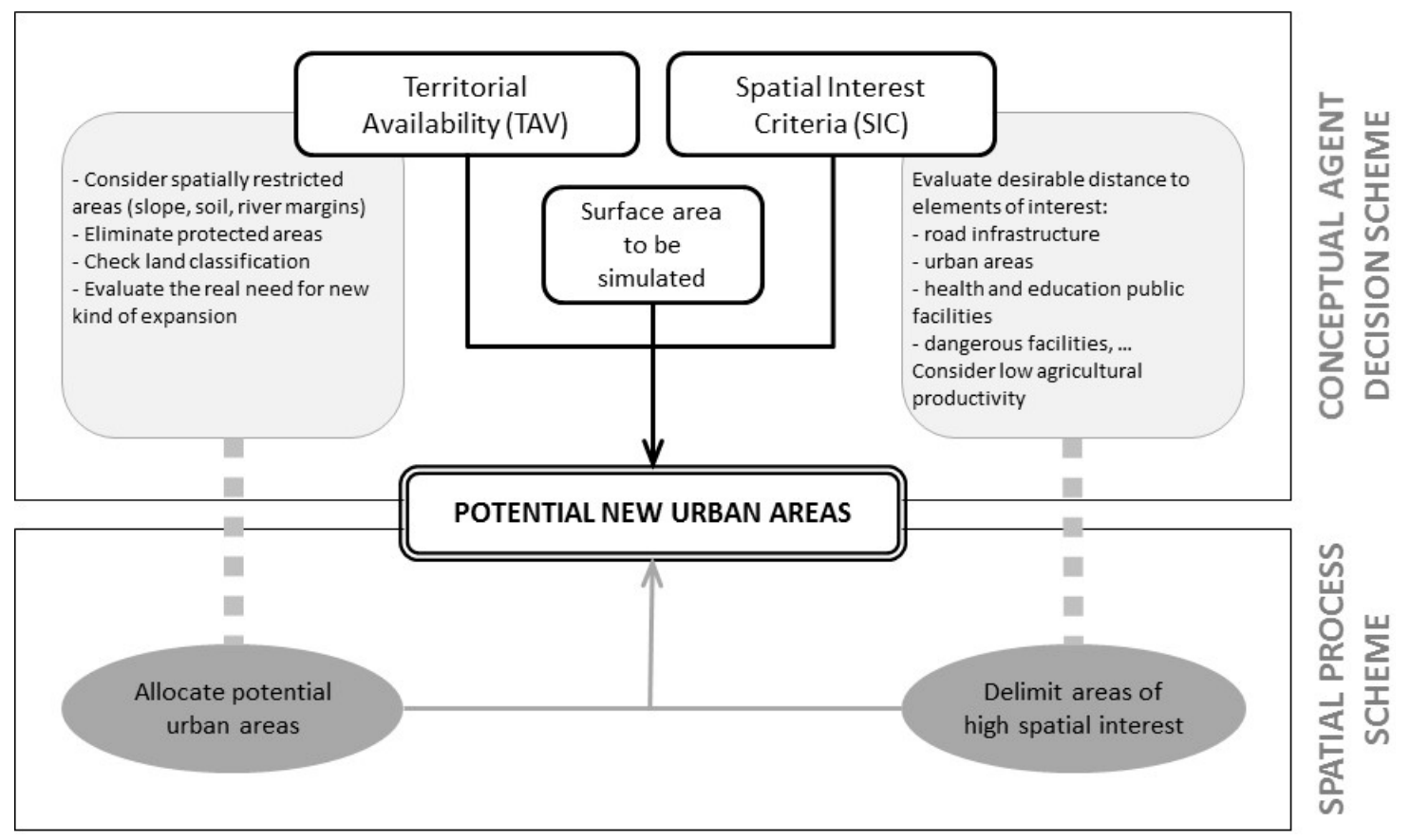

Figure 4. Conceptual decision structure of the urban planner submodel.

Besides defining the amount of land for potential reclassification as urban, the interface allows the user to set initial conditions that characterize each profile (Figure 5). Hence, the interface settings allow the user to establish weights for variables such as distance to urban areas, locally unwanted land uses (e.g., hazardous waste dumps, prisons, and trash disposal plants), road infrastructures, and health/education services, and to define priority areas for potential reclassification as urban according to their agricultural productivity.

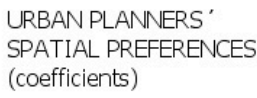

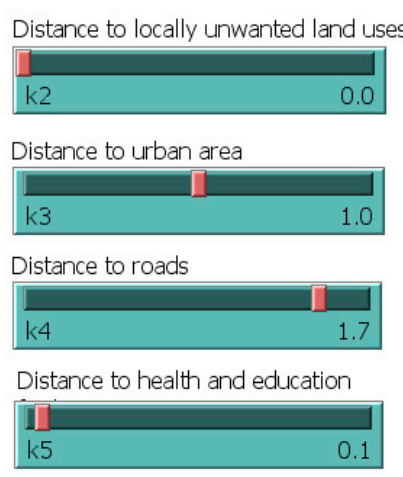

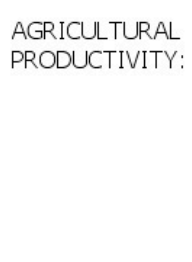

AMOUNT OF LAND FOR POTENTIAL RECLASSIFICATION AS URBAN:

$(400$ pixels $=1 \mathrm{~km} 2)$
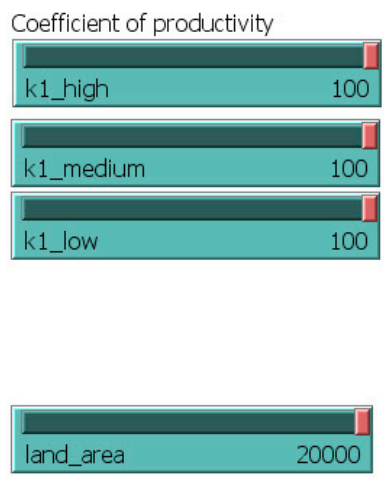

Figure 5. Variables that can be set when initializing the model to define different urban planner profiles.

The agent must convert the amount of land specified by the user in the interface, and the simulation outcomes should show where these changes will take place. The model mechanism works as follows: from among the non-restricted surface areas-limited according to user selection from among the three available options-urban planners first analyze those areas with the highest values of interest. These values are graduated using the average of the weights indicated on the sliders at the interface for each pixel (Figure 5). Then, the last coefficient (agricultural productivity) is set, and the model assumes that the proposed percentage is homogeneously distributed spatially and randomly throughout each area according to its agricultural productivity, defined as high (forest and natural areas), medium (agricultural areas), or low (all other categories) based on a reclassification of the 
CORINE Land Cover land use categories considered artificial [52]. The final selection is then taken as the best option.

Having described and implemented the conceptual model in NetLogo, the simulation experiments conducted to test the prototype are reported below. Several authors have suggested that the validation process should consist of different components: verification, validation, and a sensitivity analysis [12,53-58]. However, since this paper presents a prototype of an ABM, it focuses less on predicting the future and more on understanding and exploring the behavior of the urban system and reproducing specific scenarios. Consequently, only verification of correct model construction and validation by comparing the results with real data will be discussed further. Verification (also known as internal validation) refers to the correctness of the internal structure, ensuring that the model has been developed in a formally correct manner (e.g., system diagrams, units of measurement, and equations) in accordance with a specified methodology [58]. This implies corroborating that the implemented model conforms to the specifications by running it after changing some initial parameters, as done by other modelers [33]. Statistical validation, or just validation, refers to determining if the model is correct by checking whether it achieves the expected level of accuracy in its predictions. This involves analyzing whether the structure of the model is appropriate for its intended purpose from a conceptual and operational point of view by comparing results to real data.

The goal of these procedures was twofold: on the one hand, to confirm that the results of specific scenarios could help determine whether the model had been correctly constructed, and on the other, to confirm that the model has the capacity to generate the expected simulation, given the scale, available data, and initial set of conditions.

For verification, three different contexts were set for each model by varying some of the initial parameters (e.g., adopting a sustainable, economically conservative, or speculative approach), so that they were sufficiently diverse to generate different outputs. It is important to note that throughout this paper, the term "scenarios" is used to refer to different future contexts, rather than according to the definition of scenario in the strict sense of the term. Moreover, all of the prototype submodels represent tools in the form of open possibilities that can reproduce different urban development scenarios (as reported here) and generate a sequence of products that could be used for a validation process such as a sensitivity analysis, employed by many scientists for this purpose $[16,18,36]$. We propose to conduct such an analysis on the final model once all three submodels have been integrated.

Hence, although very different results could arise from minor changes in these initial conditions, the usefulness of the simulations resides in the fact that they were not aimed at identifying or analyzing specific urban growth shapes or statistics for the Corredor del Henares, but at determining whether the model was correctly constructed. If this latter were to be demonstrated, it would support the notion that $\mathrm{ABM}$ constitute a powerful tool for use in real situations and would confirm that the prototype achieves the proposed goal. The flexibility and high number of setting options increase the possibility of employing this tool in different contexts and using real data on other areas.

For the validation process, we compared the results of the different simulations (of the two submodels once integrated) with the corresponding urban land data available for the study area, and obtained the percentage of coincidence.

With these goals in mind, we simulated the expansion of potential development areas using three different urban planner profiles defined by the tendency to employ: (i) a sustainable approach, (ii) an economically conservative approach (typical behavior in a crisis situation), or (iii) a speculative approach (corresponding to a business-as-usual scenario), in accordance with the storyline and scenarios described in Plata Rocha et al. [50]. In order to run the three simulations, the same initial conditions were used, but different parameters were set to characterize each profile (Table 2), based on the work cited. As expected, the simulations yielded some notable differences for the three urban planner profiles, all of them with growth concentrated close to the most dynamic existing urban areas, but distributed differently throughout the territory. Other future contexts could be easily defined by changing values for each parameter. 
Table 2. Initial conditions for three different urban planner profiles.

\begin{tabular}{|c|c|c|c|c|}
\hline Variable/Urban Planner Profile & Reference & Sustainable & Conservative & Speculative \\
\hline Distance to locally unwanted land uses * & 0.0 to 2.0 & 1.0 & 0.0 & 0.0 \\
\hline Distance to urban areas * & 0.0 to 2.0 & 1.0 & 2.0 & 0.5 \\
\hline Distance to roads * & 0.0 to 2.0 & 2.0 & 1.5 & 0.5 \\
\hline $\begin{array}{l}\text { Distance to health and education facilities * } \\
\text { Agricultural productivity: }\end{array}$ & 0.0 to 2.0 & 2.0 & 1.0 & 0.0 \\
\hline $\begin{array}{l}\text { Conversion to potential building land in zones } \\
\text { with high agricultural productivity (\%) }\end{array}$ & 0 to 100 & 0 & $5 \%$ & $20 \%$ \\
\hline $\begin{array}{l}\text { Conversion to potential building land in zones } \\
\text { with medium agriculture productivity level (\%) }\end{array}$ & 0 to 100 & $10 \%$ & $20 \%$ & $40 \%$ \\
\hline $\begin{array}{l}\text { Conversion to potential building land in zones } \\
\text { with low agricultural productivity }(\%)\end{array}$ & 0 to 100 & $90 \%$ & $75 \%$ & $40 \%$ \\
\hline
\end{tabular}

* Zero indicates that this factor is not relevant, while two indicates maximum relevance. Intermediate values show proximity to minimum or maximum influence.

Therefore, the simulation results are acceptable since they are spatially and conceptually coherent. An aggregated visualization of real data on the evolution of past and recent urban plans (the municipalities in the study area have relatively old plans and many updates are under discussion) and simulation with a five-year horizon for the three planner profiles (Figure 6) indicate alternative distributions that could be used as a reference for urban planning decision-making.

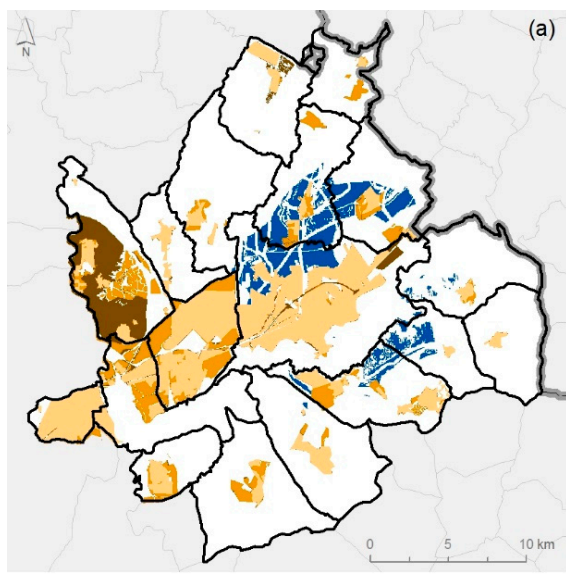

(a)
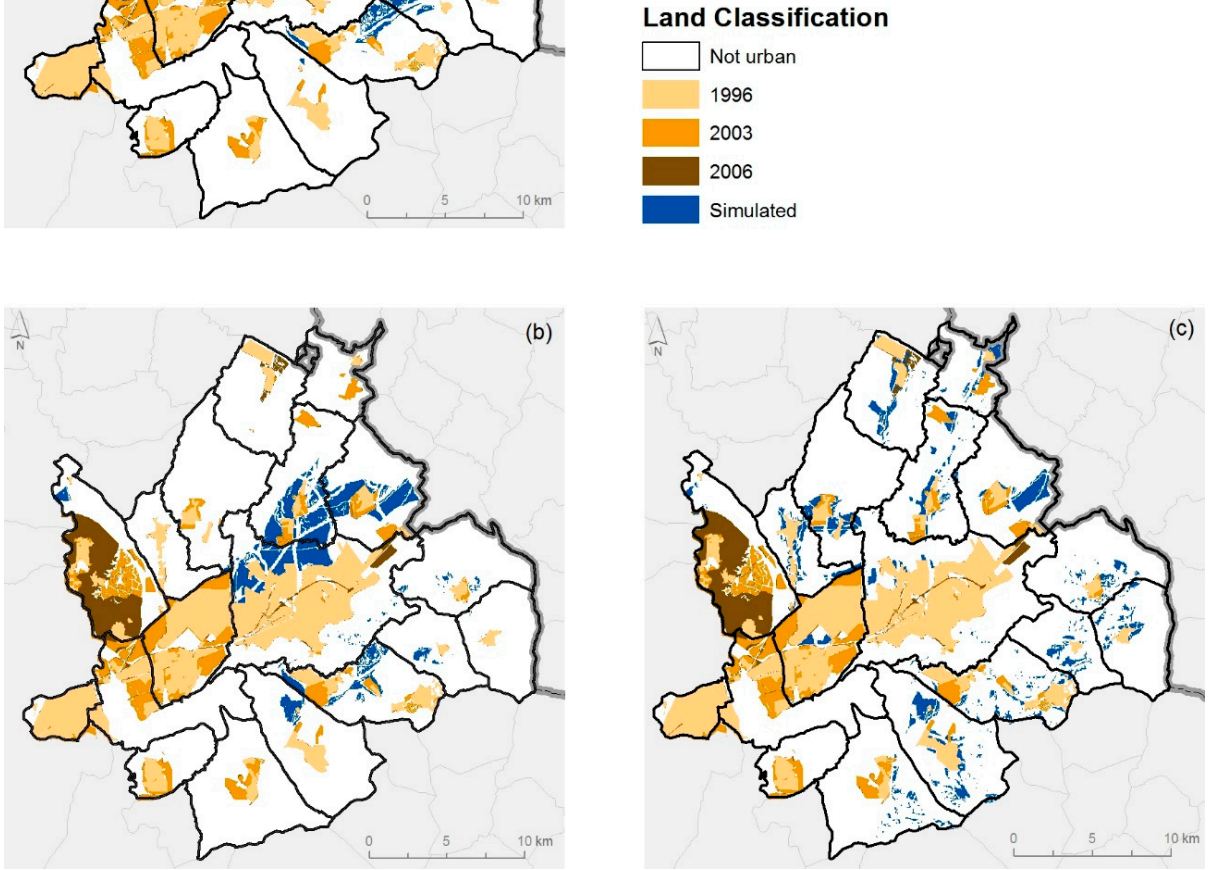

Figure 6. Comparison of simulation results (five years) and real data on past urban plans for the three planner profiles: (a) sustainable, (b) conservative, (c) speculative. 


\subsection{Developer Submodel}

The developer submodel considers a bottom-up rather than a top-down approach [27], assuming a more spatially-restricted knowledge of the territory (in the urban planner submodel, agents are assumed to be familiar with the entire territory in order to make a decision). Simulation of their behavior is expected to yield a new distribution of low, medium, and high standard residential buildings.

In the first instance, the only restrictions (TA) considered referred to regulations; thus, only alreadydesignated areas were candidates for new residential development. As regards attractiveness (SIC), the preferred distance to elements of spatial interest was defined according to the standard of the building for which expansion was to be simulated. In this model, land value and neighborhood characteristics were the two main elements that strongly affected the decision to assign a new area for development (Figure 7).

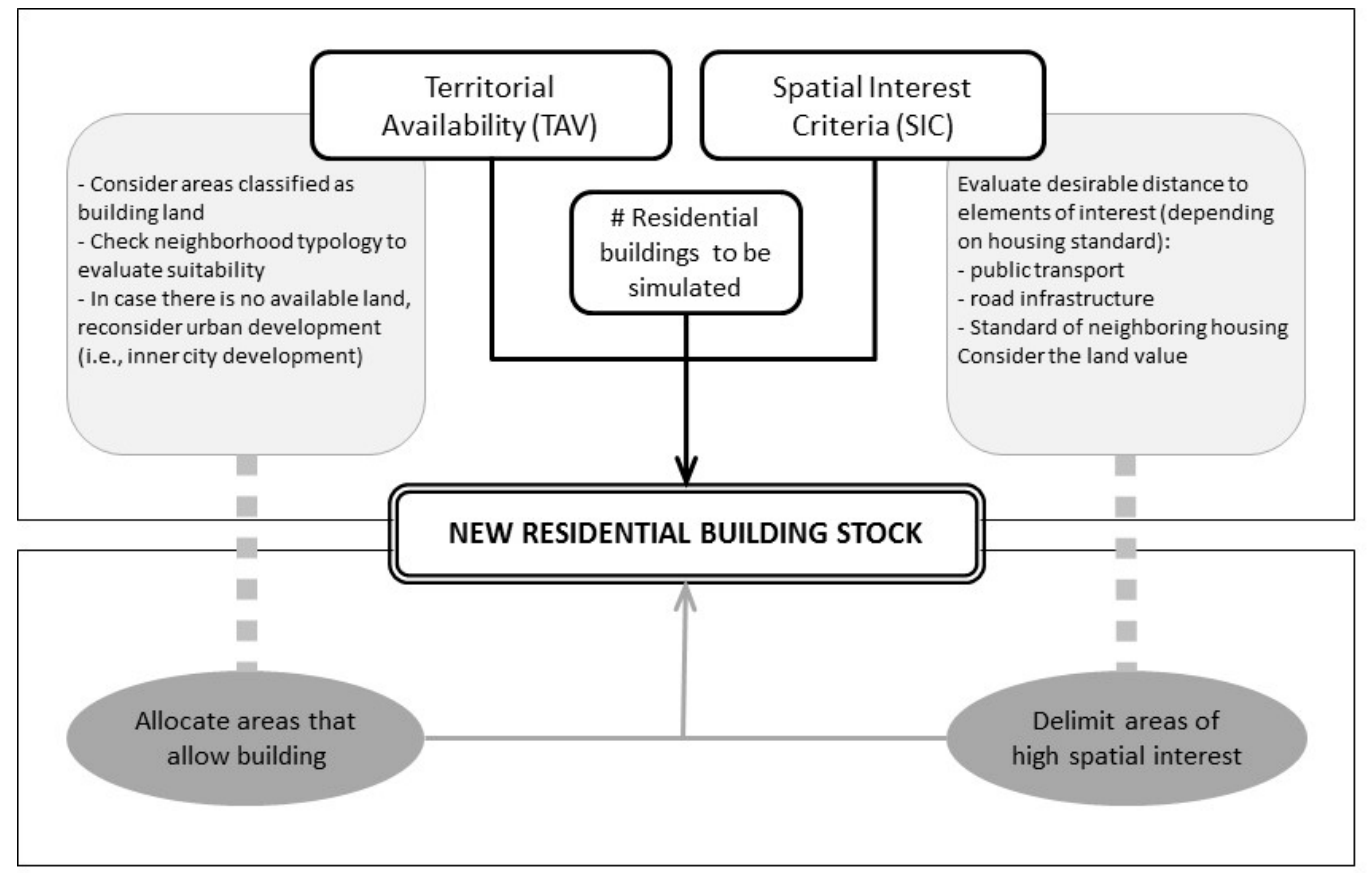

Figure 7. Conceptual decision structure of the developer submodel. \#: number.

As in the previous case, agents in this submodel present a unique type of behavior regarding the variables considered, although users may change some of the parameters depending on whether they aim to simulate the construction of high-, medium-, or low-standard housing. In addition, the interface again allows the user to establish the initial conditions by changing parameters such as the quantification of new buildings, specification of respective percentage of each type, and calibration of available coefficients for each standard (distance to roads, urban areas, and public transport). The user can also define the maximum search area that developers should take into account, considering the elements necessary to identify a suitable location (where no ideal location is identified within the area defined, the model allows the user to redefine the search area). The combination of these parameters defines the future scenario.

The decision flow chart (Figure 8) leads to the final location where new housing should be built.

Unlike the urban planner submodel, the developer submodel starts with the selection of the typology of building proposed, i.e., whether the agent will seek free land to build high, medium, or low standard housing. This information is vital to confirm the area of interest, which is different for each case, and later it will also be useful to define the number of dwellings assigned to each new building typology. This choice must respect the maximum allowed for each typology. In the next step, the model focuses on a random point that must obey the restrictions and analyzes the neighborhood, 
considering an extension which is also indicated in the interface by the user. The preference criteria include the degree of similarity with nearby buildings (attraction for similar, or in some cases, rejection for different) and the spatial interest defined as in the previous submodel. Whenever there is an option that complies with these criteria, and the maximum number of runs has not yet been reached, the new building is assigned to the corresponding pixel. The number of dwellings assigned will depend on building typology, going from high density (low standard) to low density (high standard).

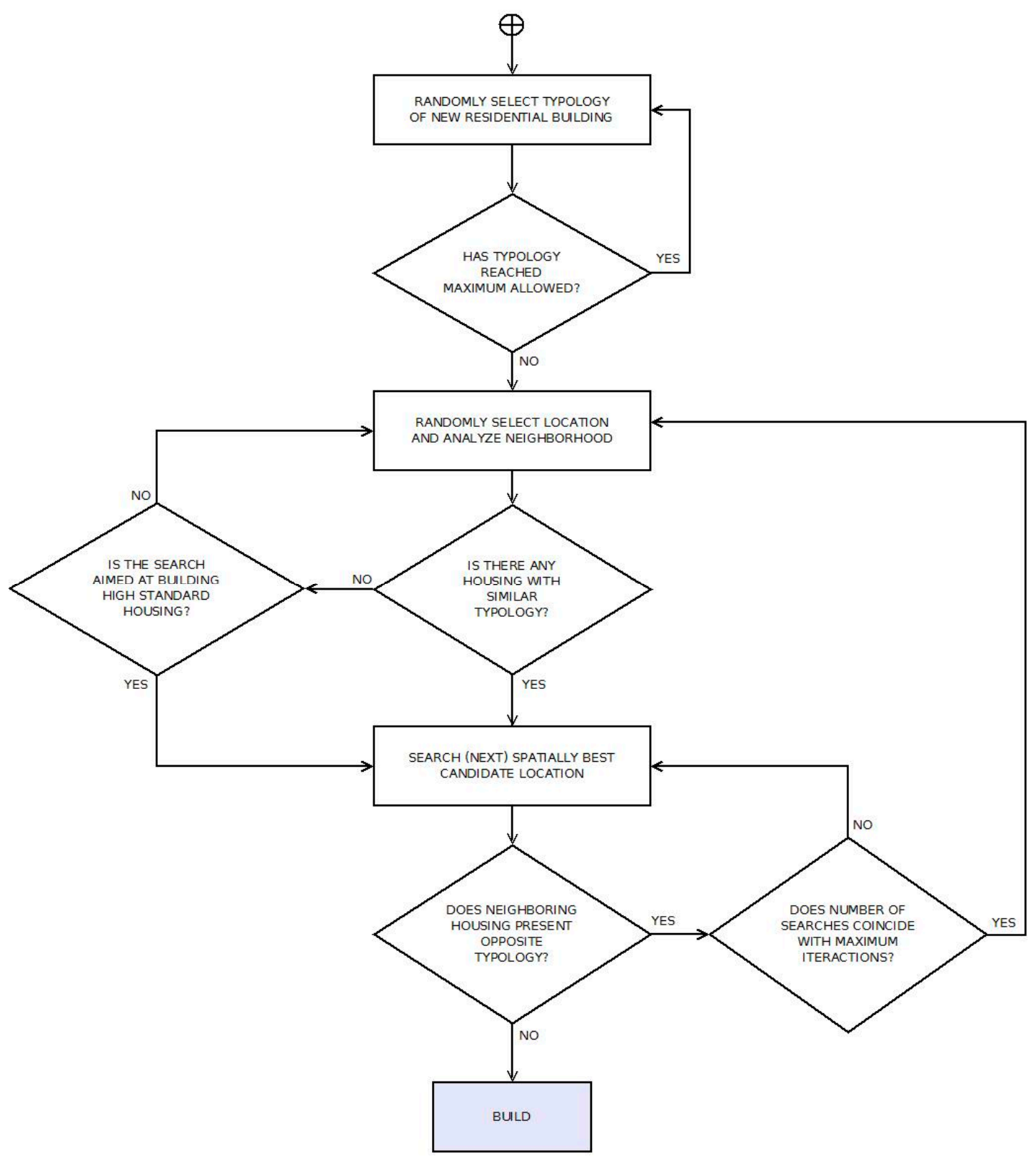

Figure 8. Developer's decision flow chart.

As in the previous case, in order to confirm prototype flexibility and correct construction, scenarios were defined according to the external environment rather than the agent's profile (as in submodel 1). In this case, two parameters could be modified: the residential growth predicted for each housing standard and the maximum search area. In order to test the model, different settings were defined for these parameters in order to simulate the real estate market under three different situations: (i) sustainable (environmental protection approach), (ii) crisis (conservative approach) and (iii) 
speculative (business as usual). Each scenario reflects different building dynamics, housing typology distribution balance, and urban growth shape, all defined by adjusting the values for the initial submodel conditions (Table 3).

Table 3. Initial settings and description of submodel spatial results from simulation of the three developer scenarios.

\begin{tabular}{|c|c|c|c|c|}
\hline Scenario & & Initial Settings & & Description of Results \\
\hline $\begin{array}{l}\text { Characteristics that } \\
\text { represent the scenario }\end{array}$ & Building dynamics & $\begin{array}{l}\text { Housing typology } \\
\text { distribution balance }\end{array}$ & Urban growth shape & \\
\hline $\begin{array}{l}\text { Equivalent parameter in } \\
\text { the submodel interface }\end{array}$ & $\begin{array}{l}\text { Number of } \\
\text { residential } \\
\text { buildings } \\
(100-3000)\end{array}$ & $\begin{array}{l}\% \text { of growth for high, } \\
\text { medium, or low } \\
\text { standard buildings } \\
(0-100 \%)\end{array}$ & $\begin{array}{l}\text { Compact or disseminated } \\
\text { represented by the search } \\
\text { area size }(50-1500 \mathrm{~m})\end{array}$ & \\
\hline Scenario 1: Sustainable & $\begin{array}{c}\text { High ( } 3500 \\
\text { new buildings) }\end{array}$ & $\begin{array}{l}\text { Balanced (high for all, } \\
\text { mean: } 70 \% \text { ) }\end{array}$ & Narrow (500 m) & $\begin{array}{l}\text { Group of buildings in a } \\
\text { compact shape, usually } \\
\text { connected to } \\
\text { existing buildings }\end{array}$ \\
\hline Scenario 2: Crisis & $\begin{array}{c}\text { Low ( } 500 \\
\text { new buildings) }\end{array}$ & $\begin{array}{l}\text { Unbalanced (low for } \\
\text { all, mean: } 30 \% \text { ) }\end{array}$ & Narrow $(500$ m) & $\begin{array}{c}\text { Few buildings, distributed } \\
\text { evenly, most of them } \\
\text { low standard }\end{array}$ \\
\hline Scenario 3: Speculative & $\begin{array}{l}\text { High ( } 3500 \\
\text { new buildings) }\end{array}$ & $\begin{array}{l}\text { Balanced (high for all, } \\
\text { mean: } 70 \%)\end{array}$ & Wide (1500 m) & $\begin{array}{l}\text { New buildings dispersed } \\
\text { throughout the territory }\end{array}$ \\
\hline
\end{tabular}

The last column in Table 3 presents a short description of the results, indicating satisfactory agreement between the proposal and the expected and simulated results, mainly considering the spatial response for the three situations (Figure 9). Furthermore, the final distribution shows the actual and projected housing together, indicating the lack of development in restricted areas (non-building areas or roads, for example). The spatial results for the developed area were generated from pixel distribution over the surface designated for that purpose (urban and developable land). We did not consider illegal settlement dynamics at this stage of the model.

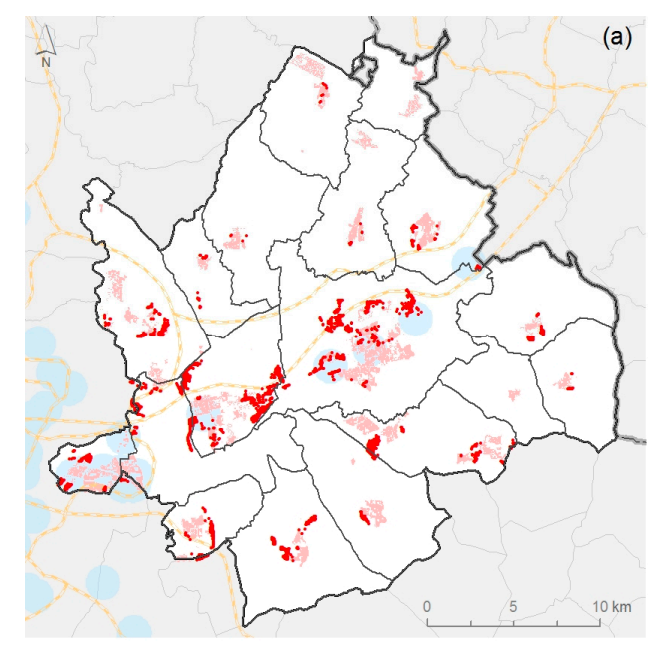

(a)

Figure 9. Cont.

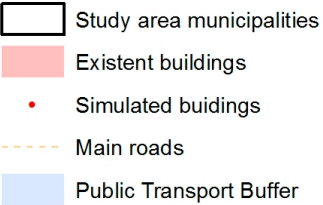



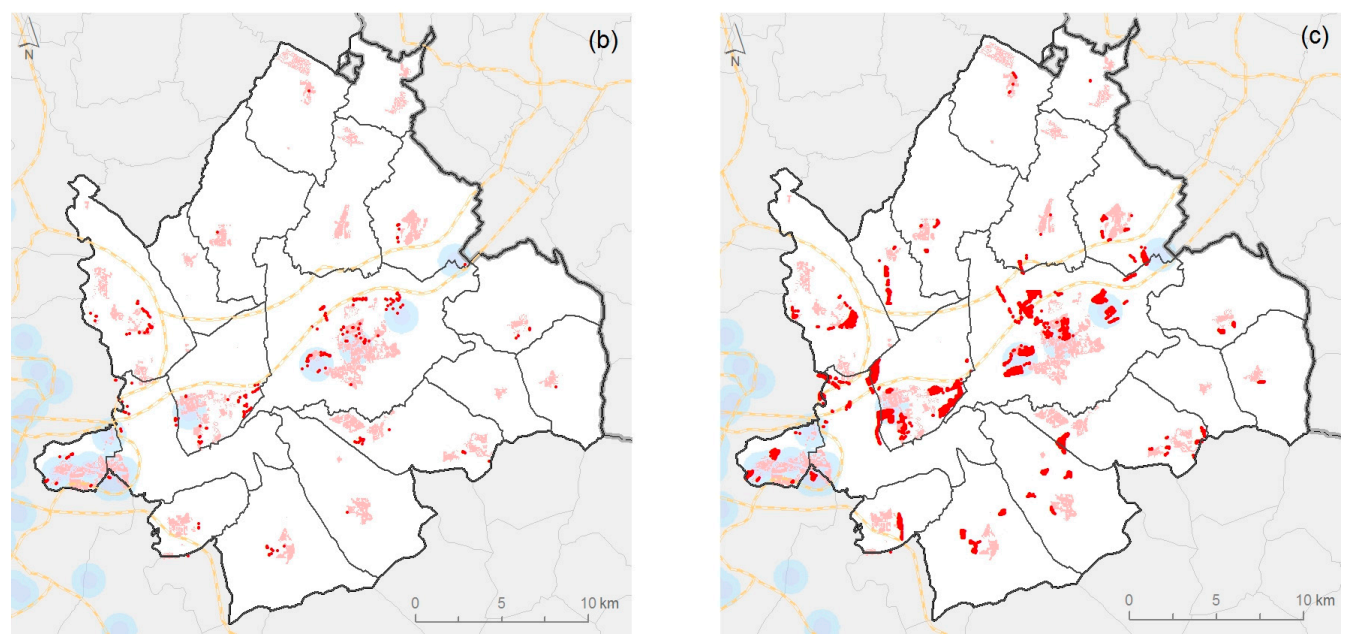

Figure 9. Spatial results for the three simulation scenarios: (a) sustainable, (b) crisis, and (c) speculative.

\subsection{Integration of the Urban Planner and Developer Submodels}

Although we only integrated two of three prototype submodels, this still presented a challenge due to the problem of how to combine two different submodels in one, which must also be clear and robust. Below, we describe how this difficulty was solved and the two submodels combined to represent the territorial expansion process:

- The submodels were combined through continuous feedback of inputs and outputs. Thus, the developer submodel uses the output of the urban planner submodel (land classification) as one of the inputs; hence, depending on the established criteria, an updated layer is periodically obtained showing areas classified as potential building land. As developers behave according to these legal restrictions, the results of the independent submodels and integrated model should differ.

- Temporal resolution also presents a challenge because the two submodels use different time intervals to reflect the fact that developers build housing in a shorter period of time than urban planners take to develop new planning proposals. By law in Spain, urban plans must be revised at least every ten years with some periodical, partial reviews; thus, five years was the interval considered for the urban planner submodel, although it could easily be modified according to where the prototype is being employed. For the developer submodel, we considered an interval of one year to reflect the time taken to construct new residential housing, although we are aware that this is often a continuous process.

- Successful integration of the two submodels depended not only on which inputs/outputs were considered, but also on when and how they were interchanged, since the submodels employ different time intervals. The rate is determined by compliance with criteria that interrupt the running of one submodel to start that of the other. In order to obtain the first results, to skip from the developer to the urban planner submodel, either (i) the free area suitable for development should not exceed a defined percentage of the total, or (ii) one of the submodels should reach a given number of runs (Figure 10).

In summary, the model starts with a territory classified into urban, potentially urban, and other, and also with a fixed distribution of buildings. The prototype internally calculates the percentage of potentially urban areas occupied by residential buildings and the number of runs for each (starting from zero). If the result exceeds the amount defined by the user (meaning that new areas are in demand), then the urban planner submodel is launched. Otherwise, the developer submodel is run continuously until that percentage is reached. Both submodels run in accordance with the independent procedures described previously. In this case, the NetLogo platform was selected in order to better 
integrate both of these with each other and with the third population submodel in an ABM context, since other techniques such as CA or multi-criteria models might not be able to solve integration.

(a)

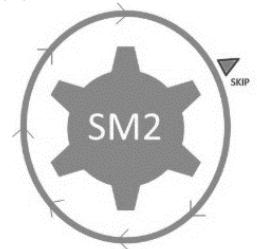

(b)

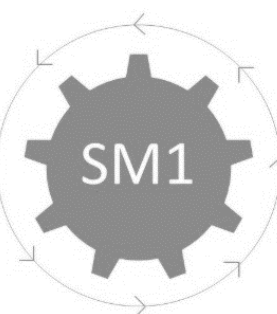

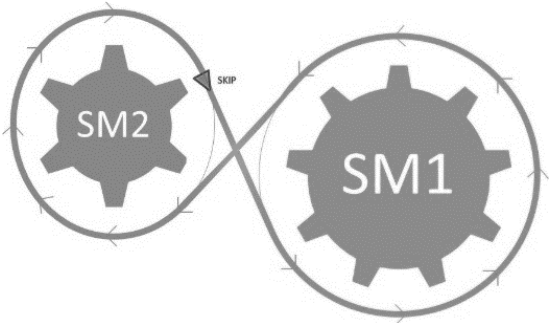

Figure 10. Sequential flow considering compliance or not with the criteria in order to skip from one model to the other: (a) Continuous cycle, (b) Cycle when "skip" conditions are met. SM1: submodel 1-urban planners; SM2: submodel 2-developers.

In order to conduct initial integration of the submodels, we considered a fixed sustainable scenario for both. In the first instance, this should represent the ideal approach to urban development, taking into consideration legal and strategic factors. Although this variable would depend entirely on the user's interests, for this simulation experiment we set the urban planner submodel to run once for each three runs of the developer submodel, with the latter running at one-year intervals. As expected, the results of this integrated simulation indicated urban growth along roads and around existing developments: potential urban land expansion occurred close to residential buildings in the smaller municipalities, and mainly in the central ones (Figure 11).

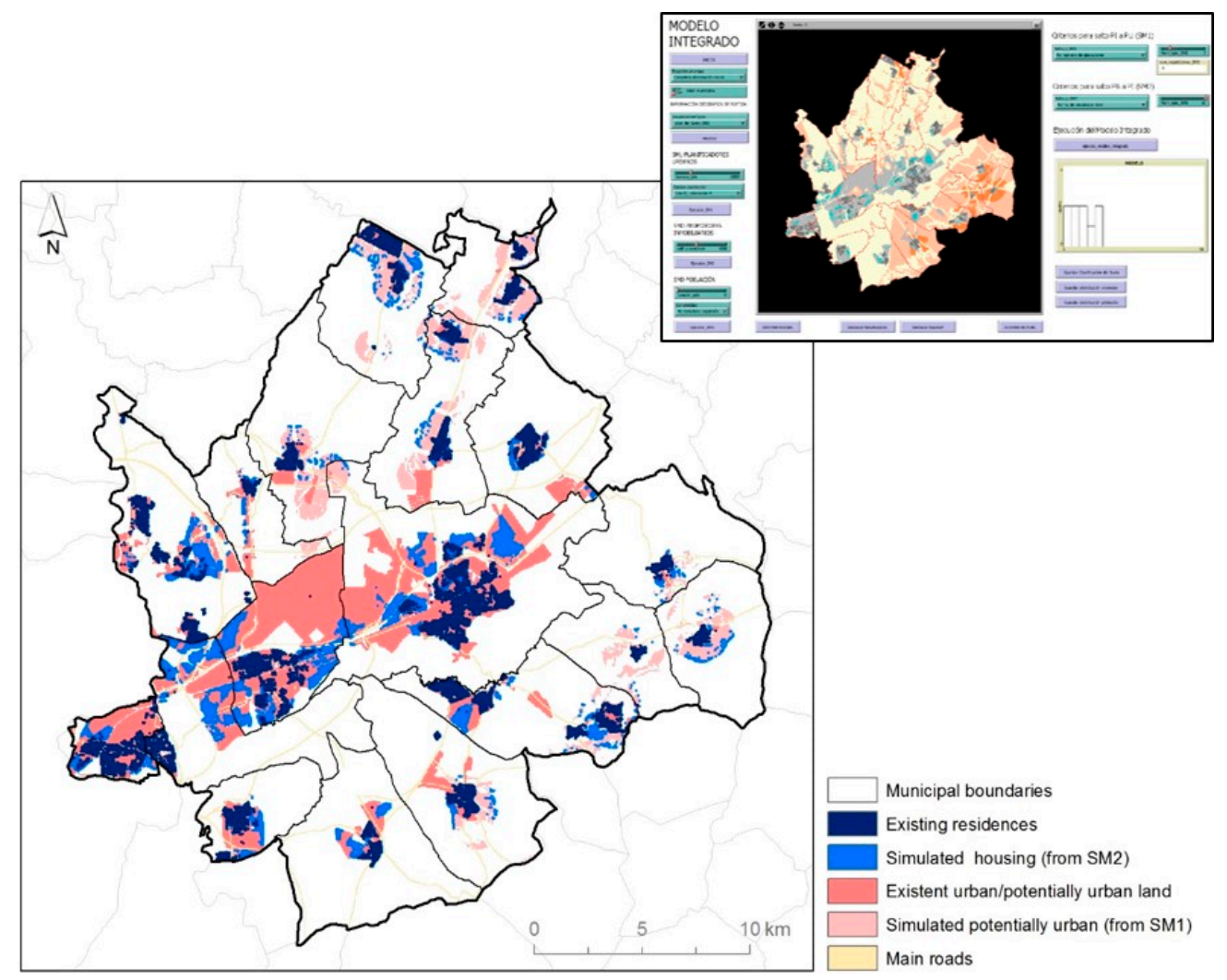

Figure 11. Interface of the model that integrates the urban planner and developer submodels and results shown in a Geographic Information System (GIS). 
The tests performed on these models represent the only verification that it was possible to conduct at this time, according to the existing data and structure described for these two submodels. Verification therefore consisted of testing model reliability by running it with different future scenarios in order to confirm that the results complied with the established rules and expected operation. This would demonstrate that the model generates acceptable simulations according to the available established parameters, and was thus considered sufficient verification for a prototype. Many partial modifications were performed throughout the construction of both submodels and the integrated model; for each procedure, additional queries were hosted in the programming to verify correct operation at different stages. An iterations routine was also introduced, and the test results achieved a mean of $90 \%$ coincidence after 10 sequential runs. This high level of coincidence is explained by the fact that the structure of both models was based on a deterministic approach.

Before reporting the validation process, it is important to note that the combined outputs of the two submodels comprise a partial result, indicating the proposed developable surface, with which there is no available real data for comparison (a comparison between different scenario outputs is given in Figure 6), and the new distribution of individual built-up pixels in those areas. With this in mind, a validation step was performed comparing the new simulated buildings with real land use data. To this end, we used the only updated data available: the Spanish Land Cover and Use Information System (Spanish initials: SIOSE) produced by the National Geographic Institute of Spain (Spanish initials: IGN), available for 2011 with a reference scale of 1:25,000. This includes the basic land use categories, such as artificial zones, crops, grassland, woodland, scrub, and land without vegetation [59]. Although the model result represents built-up areas in pixels, while the only available data on observed spatial urban growth for the same year refer to surfaces, the intersection of these shows the level of correspondence between model products and reality.

This comparison (Figure 12) revealed an acceptable level of coincidence, bearing in mind that the difference in data shape (pixel and surface) limited coincidence. In terms of percentages of correspondence, our results show that the model closely reflected the real situation in the study area tested, obtaining the highest percentage for the crisis scenario $(62.3 \%)$, which mirrored the profound real estate crisis that hit Spain during the simulation period. Furthermore, the results for the speculation scenario $(39.9 \%)$ and the sustainable scenario $(48.8 \%)$ were coherent, because the former represents the scenario furthest from reality in the study area, while the sustainable scenario indicates more conservative growth, closer to the crisis scenario (see the parameter established for each scenario in Tables 2 and 3).
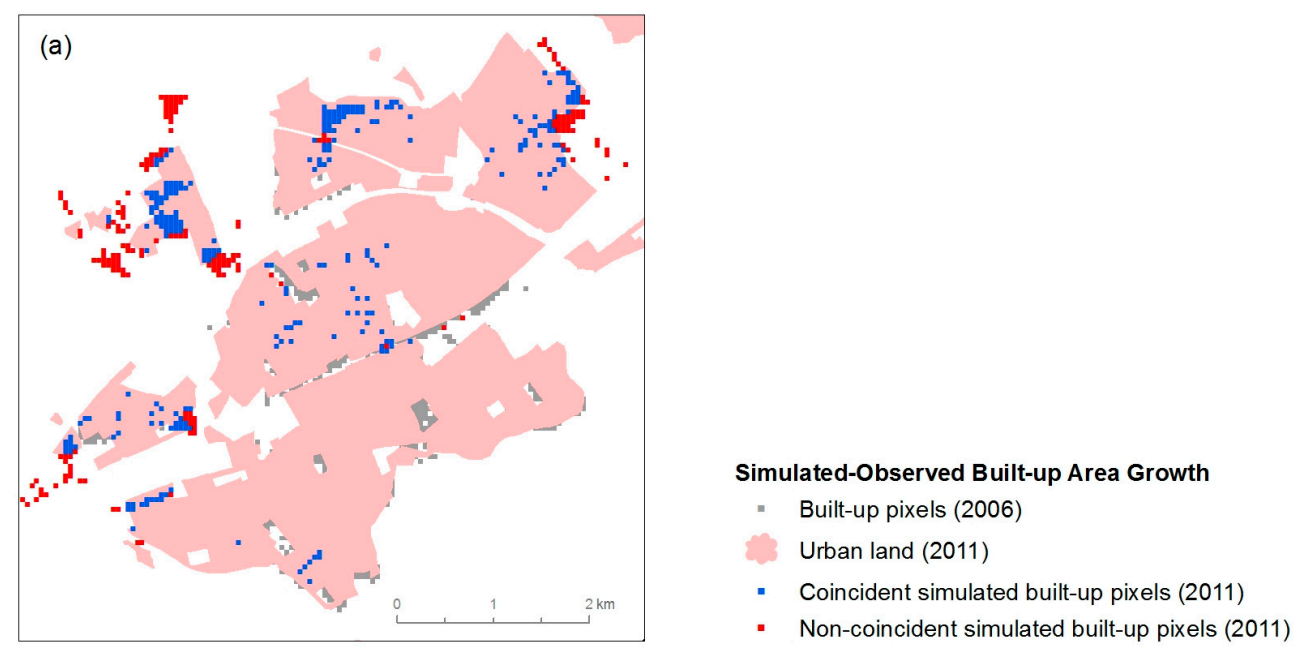

Figure 12. Cont. 

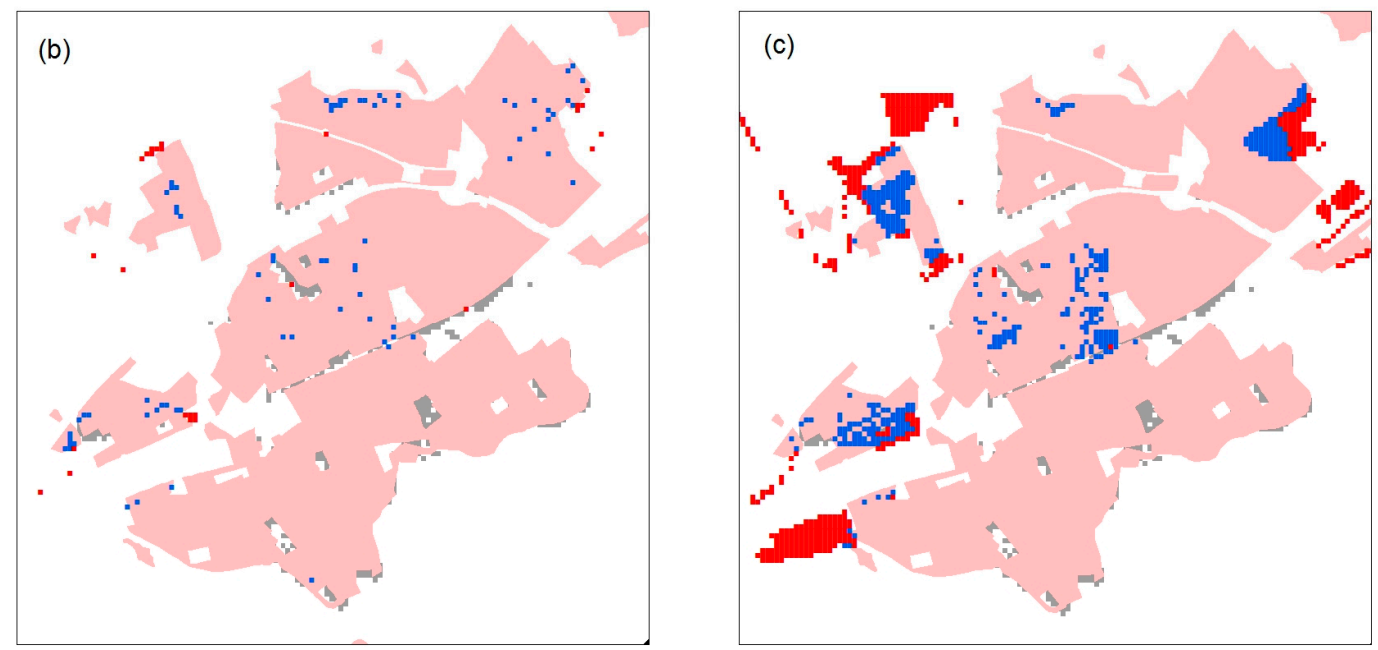

Figure 12. Simulated and observed built-up area growth in a zoomed area (municipality: Alcalá de Henares): Comparison between the simulated residential buildings for the three scenarios (pixels)-(a) sustainable, (b) crisis, and (c) speculative-and the urban land cartography (surface) from the SIOSE database (2011) [59].

\section{Discussion}

It was a challenge to design a model that simulated the urban system considering its territorial expansion process, since it was necessary to integrate two agents that act at different scales and with different goals, although their products and behaviors are closely related. A larger number of examples of application at similar scales would be required to discuss its possibilities further; nonetheless, the existing ones serve as references, to which we have added empirical knowledge about the region and the urban process in Spain, enabling us to create, run, and test both submodels and the integrated model.

The structure of the agent-based model described here consists of three agents, constructed independently for subsequent integration. When analyzed separately, the territorial expansion reported here is more deterministic, while the stochastic element is given by the third submodel (population) and the integration of the first two (as presented here) or all three submodels. The novelty of this model resides in its capacity to simulate the urban growth decision-making process in an ABM context, and to integrate the submodels, which would be problematic if using other urban growth simulation techniques such as CA or multicriteria evaluation.

It is worth mentioning that the decision to work with separate submodels, running them individually first, endowed us with more control at each step in the entire process, and in some cases it also enabled us to forestall errors. Unlike other authors, who have considered similar agents and goals [27], we used three submodels - urban planner, developer, and population-to represent the main agents when modeling the urban development process. In this paper, we have reported the first two, which together show the spatial distribution of urban growth. These agents' decisions are based on a set of criteria and weighted preferences that together with other interaction elements would be difficult to simulate using urban growth models based on multicriteria evaluation, cellular automata, or other techniques. A further innovation is the interaction of the submodels using input and output feedback in the same framework, generating a continuous process of land reclassification and residential building expansion focusing on the influence of one behavior on another. The ABM architecture facilitates the representation of agent interactions, which will be completed by integrating the population submodel, designed to represent occupation of the available residences generated by the developers.

We believe that this model, which is sufficiently flexible to combine the top-down approach of urban planners and the bottom-up approach of developers, could serve as a useful tool to stimulate 
lively discussion about planning support modeling at the intermediate scale. In addition, it could also serve to further analyze the impact of land use changes or their relationship to transport system evolution using this bottom-up perspective.

As indicated throughout this paper, this structure enabled us to combine agents' behavior and transform it into mathematical rules that could be entered independently into the urban planner and developer submodels and then transferred to the integrated model. NetLogo was the best platform for this, since its simple interface and GIS extension made it possible to obtain a user-friendly model. This capacity to connect an ABM with GIS represents an important advance for urban simulation, since there are usually clear limitations on cartographic representation in an ABM. Furthermore, the processing power of NetLogo, which may sometimes be considered a limitation for more demanding models [60,61], was sufficient in this case.

In all stages, our model works with territorial information, and thus is explicitly spatial as regards not only input but also output data. Even if the best mechanisms were available to develop an ABM, the data would represent a significant constraint if they were poor quality or did not comply with geographical and scale needs. One of the submodels' outstanding properties is their flexibility in terms of the amount and kind of data that can be used, since this allows the user to easily adapt the prototype to other similar study areas.

An analysis of the physical distribution of housing and potential urban land or a thematic analysis of the results were not among the goals of this study, although some such analyses were performed in order to confirm that the model was correctly constructed and generated accurate products. ABM validation is a controversial issue $[12,53,54,56,62-64]$, and will continue to be so until more research is conducted in this field. Nevertheless, we performed a verification procedure by means of programming tests, empirical reviews, and comparison of results, simulating growth under different contexts (setting different initial parameter values and constituting future scenarios). Furthermore, we performed a validation by comparing the simulated results to real world data, which confirmed our expectations. This step was considered sufficient since, our goal at this stage was simply to test the submodels, considering that further validation will be required in the future when the model (AMEBA) is complete, i.e., once the population submodel has been integrated.

\section{Conclusions}

In sum, the conceptual prototype, the prototype structure, and implementation of the first two submodels together represent a first attempt to create a model capable of simulating urban growth that could actually be used to support territorial planning, rather than a purely theoretical ABM. Its application at sub-regional scale using real data was a novel experiment. Therefore, considering these submodels in a wider context, the model could be useful for similar studies in different regions, provided that they presented equivalent characteristics or introduced the necessary modifications.

Acknowledgments: The findings presented here form part of the SIMURBAN2 Project (Urban Simulation Project-Part 2): Geosimulation and environmental planning tools for territorial management in metropolitan areas. Application at intermediate level (Ref.: CSO2012-38158-C02-01). One researcher was partially funded by Santander-IELAT 2015/2016. We would also like to thank the anonymous reviewers for their comments and suggestions.

Author Contributions: Carolina de Carvalho Cantergiani designed and developed the model, processed and analyzed the results under the direction of Montserrat Gómez Delgado. Both authors discussed the results and contributed on the conclusions and revisions of the document.

Conflicts of Interest: The authors declare no conflict of interest.

\section{References}

1. Berling-Wolff, S.; Wu, J. Modeling urban landscape dynamics: A review. Ecol. Res. 2004, 19, 119-129. [CrossRef]

2. Triantakonstantis, D.; Mountrakis, G. Urban growth prediction: A review of computational models and human perceptions. J. Geogr. Inf. Syst. 2012, 4, 555-587. [CrossRef] 
3. Crooks, A.T.; Patel, A.; Wise, S. Multi-agent systems for urban planning. In Technologies for Urban and Spatial Planning: Virtual Cities and Territories; Pinto, N.N., Tenedório, J.A., Antunes, A.P., Roca, J., Eds.; IGI Global: Hershey, PA, USA, 2014; pp. 29-56.

4. Bousquet, F.; Le Page, C. Multi-agent simulations and ecosystem management: A review. Ecol. Model. 2004, 176, 313-332. [CrossRef]

5. Couclelis, H. “Where has the future gone?" Rethinking the role of integrated land-use models in spatial planning. Environ. Plan. A 2005, 37, 1353-1371. [CrossRef]

6. Fernández Güell, J.M. Recuperación de los estudios del futuro a través de la prospectiva territorial. Ciudad y Territorio 2011, 167, 11-32.

7. Ligtenberg, A.; Wachowicz, M.; Bregt, A.K.; Beulens, A.J.M.; Kettenis, D.L. A design and application of a multi-agent system for simulation of multi-actor spatial planning. J. Environ. Manag. 2004, 72, 43-55. [CrossRef] [PubMed]

8. Barredo Cano, J.I.; Gomez Delgado, M. Towards a set of ipcc sres urban land-use scenarios: Modelling urban land-use in the madrid region. In Modelling Environmental Dynamics: Advances in Geomatic Solutions; Paegelow, M., Camacho Olmedo, M.T., Eds.; Springer: Berlin, Germany, 2008; pp. 365-385.

9. Díaz Pacheco, J. Ciudades, Autómatas Celulares y Sistemas Complejos. Evaluación de un Modelo Dinámico de Cambio de usos de Suelo Urbano en Madrid. Ph.D. Thesis, Universidad Complutense de Madrid, Madrid, Spain, 2015.

10. Norte Pinto, N.E.; Dourado, J.; Natálio, A. Cellular automata modeling for urban and spatial systems. In Proceedings of the International Symposium on Cellular Automata Modeling for Urban and Spatial Systems-CAMUSS, Oporto, Portugal, 8-10 November 2012.

11. Hewitt, R.; van Delden, H.; Escobar, F. Participatory land use modelling, pathways to an integrated approach. Environ. Model. Softw. 2014, 52, 149-165. [CrossRef]

12. Heppenstall, A.; Crooks, A.T.; See, L.M.; Batty, M. Agent-Based Models of Geographical Systems; Springer: Dordrecht, The Netherlands, 2012.

13. Batty, M. Cities and Complexity: Understanding Cities with Cellular Automata, Agent-Based Models, and Fractals; Massachusetts Institute of Technology: Cambridge, MA, USA, 2005.

14. Jordan, R.; Birkin, M.; Evans, A. Agent-based modeling of residential mobility, housing choice and regeneration. In Agent-Based Models of Geographical Systems; Heppenstall, A., Crooks, A.T., See, L.M., Batty, M., Eds.; Springer: Berlin, Germany, 2012; pp. 511-524.

15. Moussaïd, M.; Kapadia, M.; Thrash, T.; Sumner, R.W.; Gross, M.; Helbing, D.; Hölscher, C. Crowd behaviour during high-stress evacuations in an immersive virtual environment. J. R. Soc. Interface 2016, 13. [CrossRef] [PubMed]

16. Barros, J. Exploring urban dynamics in latin american cities using an agent-based simulation approach. In Agent-Based Models of Geographical Systems; Heppenstall, A., Crooks, A.T., See, L.M., Batty, M., Eds.; Springer: Berlin, Germany, 2012; pp. 571-589.

17. Feitosa, F.F.; Le, Q.B.; Vlek, P.L.G. Multi-agent simulator for urban segregation (masus): A tool to explore alternatives for promoting inclusive cities. Comput. Environ. Urban Syst. 2011, 35, 104-115. [CrossRef]

18. Malik, A.; Crooks, A.T.; Root, H.; Swartz, M. Exploring creativity and urban development with agent-based modeling. J. Artif. Soc. Soc. Simul. 2015, 18. [CrossRef]

19. Patel, A.; Crooks, A.; Koizumi, N. Slumulation: An agent-based modeling approach to slum formations. J. Artif. Soc. Soc. Simul. 2012, 15. [CrossRef]

20. Filatova, T. Empirical agent-based land market: Integrating adaptive economic behavior in urban land-use models. Comput. Environ. Urban Syst. 2015, 54, 397-413. [CrossRef]

21. Sun, S.; Parker, D.C.; Huang, T.; Filatova, T.; Robinson, D.T.; Riolo, R.L.; Hutchins, M.; Brown, D.G. Market impacts on land-use change: An agent-based experiment. Ann. Assoc. Am. Geogr. 2014, 104, 460-484. [CrossRef]

22. Ettema, D. A multi-agent model of urban processes: Modelling relocation processes and price setting in housing markets. Comput. Environ. Urban Syst. 2011, 35, 1-11. [CrossRef]

23. Magliocca, N.; Safirova, E.; McConnell, V.; Walls, M. An economic agent-based model of coupled housing and land markets (chalms). Comput. Environ. Urban Syst. 2011, 35, 183-191. [CrossRef]

24. Fontaine, C.M.; Rounsevell, M.D.A. An agent-based approach to model futures residential pressure on a regional landscape. Landsc. Ecol. 2009, 24, 1237-1254. [CrossRef] 
25. Parker, D.C.; Filatova, T. A conceptual design for a bilateral agent-based land market with heterogeneous economic agents. Comput. Environ. Urban Syst. 2008, 32, 454-463. [CrossRef]

26. Gilbert, N.; Hawksworth, J.C.; Swinney, P.A. An Agent-Based Model of the English Housing Market; Centre for Research in Social Simulation, University of Surrey: Guildford, UK, 2009.

27. Ligmann-Zielinska, A.; Jankowski, P. Exploring normative scenarios of land use development decisions with an agent-based simulation laboratory. Comput. Environ. Urban Syst. 2010, 34, 409-423. [CrossRef]

28. Farinós Dasi, J.; Olcina Cantos, J.; Rico Amorós, A.; Rodríguez Navarro, C.; Romero Renau, L.D.; Espejo Marín, C.; Vera Rebollo, J.F. Planes estratégicos territoriales de carácter supramunicipal. Boletín de la Asociación de Geógrafos Españoles 2005, 39, 117-149.

29. Garcia, M. The breakdown of the spanish urban growth model: Social and territorial effects of the global crisis. Int. J. Urban Reg. Res. 2010, 34, 967-980. [CrossRef]

30. Burriel, E.L. Subversion of land-use plans and the housing bubble in spain. Urban Res. Pract. 2011, 4, $232-249$. [CrossRef]

31. Burriel, E.L. Empty urbanism: The bursting of the spanish housing bubble. Urban Res. Pract. 2016, 9, 158-180. [CrossRef]

32. Filatova, T.; Parker, D.C.; Van Der Veen, A. Agent-based urban land markets: Agent's princing behavior, land prices and urban land use change. J. Artif. Soc. Soc. Simul. 2009, 12, 1-3.

33. Ligmann-Zielinska, A.; Church, R.L.; Jankowski, P. Spatial optimization as a generative technique for sustainable multiobjective land-use allocation. Int. J. Geogr. Inf. Sci. 2008, 22, 601-622. [CrossRef]

34. Haque, A.; Asami, Y. Optimizing urban land use allocation for planners and real estate developers. Comput. Environ. Urban Syst. 2014, 46, 57-69. [CrossRef]

35. Moglen, G.E.; Gabriel, S.A.; Faria, J.A. A framework for quantitative smart growth in land development. J. Am. Water Resour. Assoc. 2003, 39, 947-959. [CrossRef]

36. Magliocca, N.R.; Brown, D.G.; McConnell, V.D.; Nassauer, J.I.; Westbrook, S.E. Effects of alternative developer decision-making models on the production of ecological subdivision designs: Experimental results from an agent-based model. Environ. Plan. B 2014, 41, 907-927. [CrossRef]

37. An, L.; Linderman, M.; Qi, J.; Shortridge, A.; Liu, J. Exploring complexity in a human-environment system: An agent-based spatial model for multidisciplinary and multiscale integration. Ann. Assoc. Am. Geogr. 2005, 95, 54-79. [CrossRef]

38. Gaube, V.; Remesch, A. Impact of urban planning on household's residential decisions: An agent-based simulation model for vienna. Environ. Model. Softw. 2013, 45, 92-103. [CrossRef] [PubMed]

39. Ligmann-Zielinska, A.; Jankowski, P. Agent-based models as laboratories for spatially explicit planning policies. Environ. Plan. B Plan. Des. 2007, 34, 316-335. [CrossRef]

40. Plata Rocha, W.; Gómez Delgado, M.; Bosque Sendra, J. Desarrollo de modelos de crecimiento urbano óptimo para la cm aplicando métodos de evaluación multicriterio y sistemas de información geográfica. GeoFocus 2010, 10, 103-134.

41. INE. Spanish Statistical National Institute. 2016. Available online: www.ine.es (accessed on 15 November 2017).

42. OSE (Observatory of Sustainability in Spain). Changes in Land-Use in Spain. Implications for Sustainable Development; Mundiprensa: Madrid, Spain, 2006.

43. Miralles i Garcia, J.L.; Díaz Aguirre, S.; Altur Grau, V.J. Environmental impact on the mediterranean spanish coast produced by the latest process of urban development. In The Sustainable City 2012; Pacetti, M., Passerini, G., Brebbia, C.A., Latini, G., Eds.; WIT Press: Southampton, UK, 2012; Volume 155, pp. 379-390.

44. Gallardo, M.; Martínez-Vega, J. Three decades of land-use changes in the region of madrid and how they relate to territorial planning. Eur. Plan. Stud. 2016, 24, 1016-1033. [CrossRef]

45. ESPON (European Observation Network for Territorial Development and Cohesion). European Land Use Patterns (EU-LUPA)-Applied Research 2013/1/8; European Comission: Luxembourg, 2012.

46. Dijkstra, L.; Garcilazo, E.; McCann, P. The effects of the global financial crisis on european regions and cities. J. Econ. Geogr. 2015, 15, 935-949. [CrossRef]

47. Cantergiani, C.C.; Gomez Delgado, M. Diseño de un modelo basado en agentes para simular el crecimiento urbano en el corredor del henares (comunidad de madrid). Boletín de la Asociación de Geógrafos Españoles 2016, 70, 259-283. [CrossRef] 
48. Cantergiani, C.C.; Barros, J.; Gómez Delgado, M. How real estate agents behavior affects urban growth: An agent-based model approach. In Proceedings of the Advances in Computational Social Science and Social Simulation Congeference, Barcelona, Spain, 1-5 September 2014; Miguel, F., Amblard, F., Madella, X., Eds.; Universitat Autónoma de Barcelona: Barcelona, Spain, 2014; pp. 491-493.

49. Wilensky, U. Netlogo; Center for Connected Learning and Computer-Based Modeling, Northwestern University: Evanston, IL, USA, 1999.

50. Plata Rocha, W.; Gómez Delgado, M.; Bosque Sendra, J. Simulation urban growth scenarios using gis and multicriteria evaluation techniques. Case study: Madrid region, Spain. Environ. Plan. B 2011, 38, 1012-1031. [CrossRef]

51. Barreira-González, P.; Aguilera-Benavente, F.; Gómez-Delgado, M. Implementation and Calibration of a New Irregular Cellular Automata-Based Model for Local Urban Growth Simulation: The Mugica Model. Available online: http:/ /journals.sagepub.com/doi/abs/10.1177/2399808317709280?journalCode=epbb (accessed on 16 May 2017).

52. Corine Land Cover 2000. Nomenclature at Leval 3 (Spain). Available online: https:/ / www.europeandataportal. eu/data/en/dataset/spaignclc2000_nivel3201307180000 (accessed on 26 April 2011).

53. Qureshi, M.E.; Harrison, S.R.; Wegener, M.K. Validation of multicriteria analysis models. Agric. Syst. 1999, 62, 105-116. [CrossRef]

54. Truong, M.T.; Amblard, F.; Gaudou, B.; Sibertin-Blanc, C. To calibrate \& validate an agent-based simulation model-An application of the combination framework of bi solution \& multi-agent platform. In Proceedings of the 6th International Conference on Agents and Artificial Intelligence (ICAART 2014), Angers, France, 6-8 March 2014; pp. 172-183.

55. Acosta-Michlik, L.; Rounsevell, M.D.A.; Bakker, M.; Van Doorn, A.; Gómez Delgado, M.; Delgado, M. An agent-based assessment of land use and ecosystem changes in traditional agricultural landscape of portugal. Intell. Inf. Manag. 2014, 6, 55-80.

56. Ligtenberg, A.; van Lammeren, R.J.A.; Bregt, A.K.; Beulens, A.J.M. Validation of an agent-based model for spatial planning: A role-playing approach. Comput. Environ. Urban Syst. 2010, 34, 424-434. [CrossRef]

57. Brown, D.G.; Page, S.; Riolo, R.; Zellner, M.; Rand, W. Path dependence and the validation of agent-based spatial models of land use. Int. J. Geogr. Inf. Sci. 2005, 19, 153-174. [CrossRef]

58. Li, Y.; Brimicombe, A.J.; Li, C. Agent-based services for the validation and calibration of multi-agent models. Comput. Environ. Urban Syst. 2008, 32, 464-473. [CrossRef]

59. SIOSE. (Sistema de Información Sobre Ocupación del Suelo de España). Available online: http:/ / www.siose.es / (accessed on 15 November 2017).

60. Bajracharya, K.; Duboz, R. Comparison of three agent-based platforms on the basis of a simple epidemiological model (WIP). In Proceedings of the Symposium on Theory of Modeling \& SimulationDEVS Integrative M\&S Symposium (DEVS 13), San Diego, CA, USA, 7-10 April 2013; Society for Computer Simulation International, Ed.; Association for Computing Machinery: San Diego, CA, USA, 2013.

61. Winfrey, C.M.; Baldwin, B.A.; Cummings, M.A.; Ghosh, P. Osm: An evolutionary system of systems framework for modeling and simulation. In Proceedings of the 2014 Annual Simulation Symposium, Tampa, FL, USA, 13-16 April 2014; Society for Computer Simulation International: San Diego, CA, USA, 2014; pp. 1-8.

62. Crooks, A.; Castle, C.; Batty, M. Key challenges in agent-based modelling for geo-spatial simulation. Comput. Environ. Urban Syst. 2008, 32, 417-430. [CrossRef]

63. Heppenstall, A.; Malleson, N.; Crooks, A. "Space, the final frontier": How good are agent-based models at simulating individuals and space in cities? Systems 2016, 4, 9. [CrossRef]

64. Filatova, T.; Verburg, P.H.; Parker, D.C.; Stannard, C.A. Spatial agent-based models for socio-ecological systems: Challenges and prospects. Environ. Model. Softw. 2013, 45, 1-7. [CrossRef]

(C) 2017 by the authors. Licensee MDPI, Basel, Switzerland. This article is an open access article distributed under the terms and conditions of the Creative Commons Attribution (CC BY) license (http://creativecommons.org/licenses/by/4.0/). 